\title{
AGRANULOCITOSIS EN UN LACTANTE DE 4 MESES
}

\author{
Drs. ROBERTO KOHAN, NORMA PESSE y ALEJANDRO RIED \\ Cátedea de Pediatcía del Prof. Adalbetto Steeger y Servicio de Pediatría \\ del Prof. Julio Schwarzenberg. Hospital "San Juan de Dios". Santiago.
}

Por la rareza de este cuadro en la edad del lactante, hemos estimado de interés la publicación del siguiente

\section{CASO CLÍnICO}

O. P. P. (Ots. 150344 ), 4 meses 16 dias. 3.100 gr. Talla: $52.5 \mathrm{~cm}$. Citcunsferencia craneana, $36 \mathrm{~cm}$. Circunsferencia torácica, $30,5 \mathrm{~cm}$. y tempetalura tectal, $37^{\circ}$. El estado general era malo y el niño sc notaba pálido, decajdo y quejumbroso. La piel era aspera, seca y con escleredema de las extremidades inferiores. En la región inguinal derecha se notaba un zona ulcerada. de unos $3 \mathrm{~cm}$. de largo, de fondo os curo y seco, de bordes netos, indurados $y$ rojos, sin reacción ganglionar. Además, en la región sacra se observaban 7 u 8 pequeñas heridas tedondeadas. um. bilicadas, enrojecidas $y$ sin secreción. Finalmente, en las regiones palpebrales llamaba la atención una lesión úlceto-necrótica, más marcada a la izquierda. El bi. gado estaba a $3 \mathrm{~cm}$. deì reborde costat y el bazo no se palpaba.

Revisados los antecedentes. sabemos que la madre de este niño es una joven de 15 años de edad, que habría sufrido una dermatitis seborreica antes del año de edad, de bronquitis asmática y de glomérulo-nefritis aguda en la segunda infancia. El padre, primo. hermano de la madre. tiene 20 años de edad $y$ es sano.

Se rrata de un primer hijo, nacido en parto prematuro, normal, en el Hospital "San Borja". Es alimentado al seno materzo, hasta el mes $y$ medio de edad; desde esta fecha se agrega telleno de Eledón en dosis suficiente. A pesar de la alimentación adecuada, e] niño no progresa. Lo notan decaido y pálido. Atendido en un Centro de Salud, se le indica Vitamina D2 300.000 unidades por vía oral. Sigue decaido y el médico considera necesaria lana cura con penicilina, a razón de 400.000 anidades diarias, darante 5 días. Terminado este tratamiento. aparecen las lesiones úlcero-necróticas de los párpados y de la tegión inguinal derecha, Esta última se abre espontaDeamente $y$ no dá salida a secreción alguna. Por tal razón, es hospitalizado en nuestro Servicio.

Con todos estos antecedentes y el examen físico a la vista, no pudimos, en un principio, llegar a un diagnóstico preciso. Se pensó en la sífilis, en la tubetculosis, en una infección banal en un distrófico grave.
Se lracia indispensable rectrif al laboratorio para tratar de llegar a una conclusión que estuviera de acuctdo con la realidad. Las keacioncs de Mantoux al uno por mil. de Kahn, la radioscopia del tórax y el hemocultivo, resultaron negativos. Las muestras bacteriológicas de las úlceras palpetrales, inguinal derecha y sacrococcigea dieron. como gérmenes comunes, diplococeus pneumoniaz, csiherichia coli y pseadomonas aeruginosa. sensibles a! cloramfenicol.

Un primer hemograma dió:

Gióbulos rojos: $3.900 .000 \times \mathrm{mm}^{3}$.

Hemoglobina: $80 \%=12,4 \mathrm{gr}$.

Valor globular: 1,05 .

Hematocrito: $34 \%$.

Leucocitos: $2.100 \mathrm{x} \mathrm{mm}^{3}$.

Eos. 4: segm. 1: linf. 62: mono. 28: plasmazelien 2: células reticulonendoteliales 3 .

Plaquetas normales al frotis.

Con el resuleado de este examen, el cuadro se aclaraba: se trataba de una agranalocitosis que perfecta. mente podia explicar las características clinicas que presentaba el enfermito. Para mayor seguridad. Se repitc el hemograma, dos dias después, que no hace sino consolidar el primer diagnóstico.

El mielograma, por punción esternal. informaba lo siguiente:

Mieloblastos 7 (Normal: $1.17 \%$ ).

Serie granulocitica:

$\begin{array}{lccr}\text { Promiclocitos neutrófilos } & 40.5 & \text { (N. 1.25) } \\ \text { Miclocitos neutrófilos } & 6 & \text { (N. 12.67) } \\ \text { Juveniles neutrófilos } & 0.5 & \text { (N. 20.31) } \\ \text { Juveniles eosinófilos } & 1.5 & (\mathrm{~N} .1 .1) \\ \text { Baciliformes neutrófilos } & 0 & (\mathrm{~N} .14 .4) \\ \text { Baciliformes eosinófilos } & 0 & (\mathrm{~N} . & 0.6) \\ \text { Polinncleares zeutrófilos } & 0 & \text { (N. 15.8) } \\ \text { Polinucleares cosinófilos } & 0 & (\mathrm{~N} .0 .6)\end{array}$

Serie exitsocitica:

Pronormoblastos

3.5 (N. 0,9 )

Normoblastos basófilos

(N. 3,7$)$

Normoblastos policromáticos

(N, 15,8 )

Serie trombocitica:

Megacarioblastos

Megacariocitos
(N. 0.1 )
0 (N. 0.6 ) 
Otras célutas:

$\begin{array}{lrrr}\text { Monocitos } & 6 & \text { (N. 1,5) } \\ \text { Linfocitos } & 13 & \text { (N. } 3.4) \\ \text { Plasmazellen } & 1 & \text { (N. } 1,2 \text { ) } \\ \text { Céldalas reticulovendoteliales } & 6 & \text { (N. } 0,1)\end{array}$

Interptetación :

(Mielograma efectuado en 200 células. Recueuto celulat: $25.000 \times \mathrm{mm}^{3}$ ). Aumento marcado de los promielocitos neutrófilos, disminación de los mielocitos y juveniles, ausencia de los baciliformes y polinucleares.

Series eritrocitica y trombocitica, normales. Conclusión: lo más probable es que se trate de una agranulocitosis. Es imposible eliminar el diagnóstico de leucemia aguda, pero es poco probable, ya que el nú. mero total de elementos está disminuido y las series eritrocitica y trombocítica están conservadas.

Se hace tratamiento con penicilina. 400.000 unidades diarias, transfusiones sanguíneas, día por medio. y curación de las lesiones palpebrales y de ta región inguinal derecha. Pero, al tercet día de hospitalización, se compraeba disminución de la sonoridad en el campo pulmonat izquierdo con crépicos en esta región. La radioscopia muestra sombras difusas que abatcan casi la totalidad del pulmón izquierdo. Al día siguiente, el niño se agrava: tiene vómitos sanquinolentos, está desbidratado y el abdomen se halla distendido e intensamente meteorizado y el mismo día faHlece.

Efectuada la autopsia, al día sigaiente de su fallecimiento, el examen histológico dá los siguientes datos:

En la medula ósea. se observa hematopayesis activa eritroblástica. La leucopoyesis es escast y no se eneuentran leucocitos polinucleares: bay anmento relativo de las células plasmáticas y linfocitos (Fig. No 1). En la pié. en el punto cortespondiente a la úlcera inguinal derecha, se comprueba una pérdida de substancia con formación de una costra. La lesión com-



Fig. Na l. - Medula esternal. Se observa ausencia de las formas maduras de la serie grapulocitica.

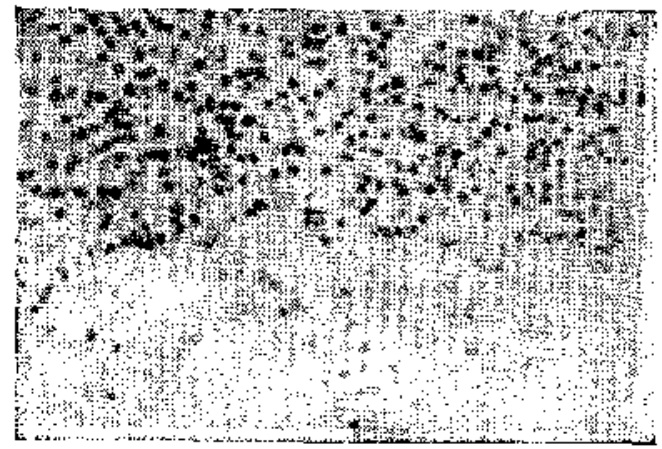

Fíg. No 2. - Piel. Se observa an infiltrado inflamatorio constituido exclusivamente por linfocitos en la hipodermis.

promete basta la parte más superficial de la hipodermis y se caracteriza por la presencia de focos de necrosis con un exudado inflamatorio en el que se reconocen abundantes linfocitos. Hamando la atención la ausencia de polinucleares (Fig. No 2). En los pulmones, sobre todo el izquierdo, se observa que los alvéolos de los lóbulos inferiores están llenos de un material grumoso $y$ de un exudado inflamatorio, constituido pot linfocitos. En los riñones, algonos gloméralos presentar pequeños focos de esclerosis y en el nef tón distal se visualiza uno que otro cilindro bialino.

La tinción de Gram, efectuada en los cortes de pulmón y de la úlcera cutánea, revela la presencia de escasas colonias microbianas, constitujdas por cocos Gram (+) -especialmente estafilo y estreptococcus.

\section{COMENTARIo}

La agranulocitosis aguda, del tipo descrito por Schultz, en 1922, es una enfermedad propia de la mujer de la mediana edad. En la infancia es rara, extraordinariamente rara, y la mejor demostración es que, hasta 1937 , Plum, citado por Erika Bruck y por Armas Cruz ${ }^{1.2}$ sólo pudo encontrar 9 casos que llenaban los requisitos de la agranulocitosis pura. Glanzmann ${ }^{3}$, en 1951, habla de 13 casos en la infancia, de los cuales 10 corresponden a niñas y sólo tres a varones.

El proceso se caracteriza por una depresión de la médula ósea, que dá como resultado una detención de la maduración o completa destrucción de la serie granulocítica. En los casos puros, no hay alteración de los glóbulos rojos ni de las plaquetas. 
Desde que Schultz describió esta afección, mucho se ha discutido si se trata o no de una enfermedad "sui-géneris". Así, hay autores que creen que la agranulocitosis es sólo una manifestación de una reacción constitucional del organismo a una infección séptica. Zadek, citado por Empey y Croescher ${ }^{4}$ es de opinión que la agranulocitosis es debida a una reacción anormal individual del aparato granulocítico. A su vez, los que sostienen que realmente se trata de una enfermedad. creen que la ausencia de diátesis hemorrágica, trombopenia $\mathrm{y}$ el estado anormal de la serie eritroblástica, son signos definitivos aue sólo el sistema granulocítico está dañaro por una noxa específica.

En el adulto. se parte de la base que la afección es debida a drogas. como consecuencia de intolerancia o de alergia. Se produciría un shock alérgico sobre la médula ósea que dificultaría la maduración v movilización de la serie celular mieloide.

Entre los medicamentos capaces de producir esta reacción sobresalen el piramidón, sus derivados y las sulfas. Sin embargo, nuestra práctica pediátrica permite afirmar que, por lo menos, entre nosotros, el piramidón no provoca los trastornos aue se han descrito en el adulto; aún más, Glanzmann es categórico en afirmar que dicho medicamento no interviene en la génesis de la agranulocitosis de la infancia.

Por otra parte, a Niemeyer y Eberhard 5 "les llama la atención la extraordinaria tolerancia de nuestros lactantes a la acción de medicamentos sulfamídicos" y nosotros compartimos ampliamente esta manera de pensar. Estos autores recuerdan que en numerosos niños, en su mayoría distróficos, han practicado rutinariamente un hemograma por semana, durante largo tiempo, y no han comprobado, con excepción de un solo caso, la acción perniciosa atribuible, con seguridad a la sulfo-droga. Precisamente, en su tiabajo presentan una observación de un lactante distrófico, en el que aparece el cuadro bematológico de una agranulocitosis, sin síntomas clínicos, y atribuible a la acción tóxica de drogas sulfamídicas.

Cooley ${ }^{6}$ afirma que debe haber cierta susceptibilidad 0 alergia. Insiste en que muchos pacientes han tomado aminopirina 0 alguno de los barbitúricos, $\mathrm{y}$, sin embargo, sólo en escaso número reaccionan con agranulocitosis, seguramente en relación con dicha susceptibilidad. Como en otros pacientes no se descubre causa alguna, habría que invocar otros alergenos no bien conocidos.

Etiológicamente, Cooley hace la siguiente clasificación:

1. Agranulocitosis por drogas.

2. Agranulocitosis sintomática de procesos séptícos o tóxicos.

3. Agranulocitosis de causa desconacida.

E1 cuadro clínico se presenta como un proceso infeccioso grave con la presencia, generalmente, de lesiones úlcero-necróticas de las mucosas, de preferencia de la cavidad bucal. Otras localizaciones, como la comprobada en nuestro caso, son raras.

E1 diagnóstico certero lo dá el hemograma, caracterizado por la ausencia o disminución de los granulocitos. El mielograma revela la desaparición de los granulocitos maduros, así como de los baciliformes y de los mielocitos maduros. Quedan los mielocitos, promielocitos y mieloblastos juveniles, cuyo número va en aumento.

El diagnóstico diferencial debe hacerse especialmente con la leucemia y la anemia aplástica. En la agranulocitosis, el descenso marcado de los granulocitos no va acompanado de disminución de los eritrocitos y de las plaquetas, mientras que en los otros dos procesos, están afectadas las tres series.

El tratamiento se basa, en la actualidad, en el uso simultáneo de los antibióticos, especialmente la penicilina, y las transfusiones sanguíneas.

La ACTH y la cortisona constituyen los dos recursos más modernos; su acción estimuladora sobre la médula ósea, justificaría su empleo.

\section{FESUMEN}

Se relata el caso de un lactante de $4 \mathrm{y}$ medio meses de edad, con una distrofia avanzada, que presenta lesiones necróticas de los párpados y una ulceración de la región inguinal derecha, sin secreción, ni compromiso ganglionar.

El hemograma y el mielograma dieron el diagnóstico de agranulocitosis. Además, 
la falta de antecedentes sobre uso de piramidón y sus derivađos y sulfas, llevó a la conclusión de que se trataba de una agranulocitosis pura, tipo Schultz, enfermedad que es extremadamente rara en la primera infancia.

\section{SUMMARY}

\section{Agranulocytosis IN A 4 MONTHS OLD} INFANT.

It is reported a case of a four and a half months old baby with an advanced dystrophia, who presented necrotic lesions of the eyelids and a ulcer in the right inguinal region, without secretion and no compromise of limph nodes.
The white blood cells count and the bone-marrow cells count gave the diagnosis of agranulocytosis.

Furthermore, the lack of antecedents about the use of pyramidon and his derivates and sulfas, brought us to the conclusion of a pure agramulocytosis, Schultz's type, disease which is extremely rare in infancy.

\section{BIBLIOGRAFÍA}

1.- RkITCK, F. - Am. J. Jis, Chi.A, 33:186. 1947,

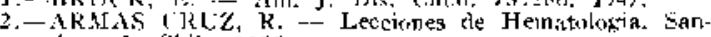
tiago le Cbile. 3955

3.-CISANZMANN, E. --- Jectiones de F'cliatria. lid. JálHics. $19+2$.

4.-EACPF, L. W, y l'ROESCHFR, F. - Am, J. Dis

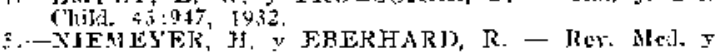
Alinent, $7: 39,1946$

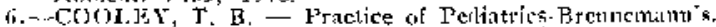
Fol. III, Cap. 16, Pag. 76. W, F. Fring. 1948. 